\title{
Expressões da violência na escola: relações paradoxais presentes nas publicações científicas brasileiras
}

\section{Expressions of violence in the school: paradoxical relations in Brazilian scientific publications}

\author{
Expresiones de la violencia en la escuela: relaciones \\ paradójicas presentes en publicaciones científicas brasileñas
}

\author{
Karin Cristina de Souza Moraes Magalhães* \\ Universidade Federal de Goiás - UFG, Goiânia, Goiás, Brasil \\ Sheila Daniela Medeiros dos Santos** \\ Universidade Federal de Goiás - UFG, Goiânia, Goiás, Brasil
}

\begin{abstract}
RESUMO
Esta pesquisa objetiva analisar o modo como as expressões da violência, no contexto escolar, são problematizadas pelas principais publicações acadêmico-científicas nacionais na atualidade. Para efetivar esse estudo de cunho marcadamente teórico realizou-se um levantamento bibliográfico das principais produções teóricas no período de 2000-2013: livros que constam na base de dados da Biblioteca Nacional do Rio de Janeiro, depositária do patrimônio bibliográfico e documental do Brasil, e artigos científicos publicados em periódicos nas áreas da Educação e da Psicologia. Os estudos realizados, fundamentados na Psicologia Histórico-Cultural (Vigotski, 1997, 2004), apontaram para o fato de que as expressões da violência na escola referem-se a elementos mediadores concretos da cultura instituídos pela atividade consciente do homem. Conclui-se que um caminho plausível para minimizar a violência na educação escolar aponta para a ênfase em práticas participativas na relação entre a escola e a comunidade, a concretização da cidadania e o reconhecimento da dignidade humana.
\end{abstract}

Palavras-chave: psicologia histórico-cultural, violência, escola.

\begin{abstract}
This research aims to examine how the expressions of violence in the school context are problematized by major national academic and scientific publications today. To carry out this study of markedly theoretical nature, we performed a bibliographic survey of the main theoretical productions in the period between 2000-2013: books contained in the database of the National Library of Rio de Janeiro, a depository of bibliographic and documentary heritage of Brazil, and scientific articles published in journals in the fields of Education and Psychology. The studies were conducted based on Cultural-historical Psychology (Vigotski, 1997, 2004) and they pointed to the fact that expressions of violence in school relate to concrete mediating
\end{abstract}


elements of the culture established by the conscious activity of men. The conclusion states that a plausible way to minimize violence in education points to an emphasis on participatory practices in the relationship between school and community, the realization of citizenship and the recognition of human dignity.

Keywords: cultural-historical psychology, violence, school.

\begin{abstract}
RESUMEN
Esta investigación tiene como objetivo examinar cómo las expresiones de violencia en el contexto escolar se problematizan por las principales publicaciones académicas y científicas nacionales hoy. Para llevar a cabo este estúdio de carácter teórico se realizó un estudio bibliográfico de las principales producciones teóricas en el período 2000-2013: los libros que figuran en la base de datos de la Biblioteca Nacional de Río de Janeiro, depositaria del patrimonio bibliográfico y documental de Brasil, y artículos científicos de revistas de los campos de la educación y la psicología. Los estúdios, basados en Psicología Histórico Cultural (Vigotski, 1997, 2004), señalaron el hecho de que las expresiones de violencia en la escuela se relacionan con elementos concretos mediadores de la cultura establecidos por la actividad consciente del hombre. Es la conclusión de que una manera plausible de minimizar la violencia en los puntos de enseñanza al énfasis en las prácticas participativas en relación entre la escuela y la comunidad, realización de la ciudadanía y el reconocimiento de la dignidad humana.
\end{abstract}

Palabras clave: psicología histórico cultural, violencia, escuela.

\title{
1 I ntrodução
}

O problema da violência nas escolas no Brasil não surgiu de modo imprevisível ou a partir de fatores desconhecidos. Esse problema está intimamente relacionado às relações sociais e à história econômica e cultural de nosso país, o que exige um olhar atento para a contemporaneidade ${ }^{1}$.

Para circunscrever e problematizar a temática da violência na escola é necessário relacioná-la intrinsecamente à sociedade, lugar onde se origina e se manifesta. Por conseguinte, o debate sobre a violência nas escolas no Brasil requer a análise de seu significado histórico, cultural e social, uma vez que o fenômeno da violência na sociedade contemporânea adquire uma razão inversamente proporcional ao seu movimento discursivo (Bakhtin, 1988).

Nesse ponto, torna-se evidente que, face ao universo ideológico neoliberal e pós-moderno, as discussões controversas endossadas e divulgadas nos vários panoramas sociais não apenas desvelam a urgência em encontrar propostas alternativas para refrear e/ou minimizar a violência, como também apontam para a necessidade de implementar políticas de segurança pública efetivas.

De acordo com Sposito (2001), apesar da temática 'violência na escola' ser relevante e premente no Brasil, apenas no início da década de 1980, a partir da proposta de redemocratização do país, o debate sobre a relação entre a violência e a escola tornou-se objeto 
de estudo legítimo no meio público e acadêmico, recebendo a atenção do Estado e da imprensa escrita e eletrônica como um problema social.

Com o passar dos anos, embora o predomínio de pesquisas no domínio nacional ainda seja incipiente, questões fundamentais são levantadas e incitam o surgimento de novos estudos, como os de Abramovay \& Castro (2006), Guimarães (2010), Patto (2007), Pino (2007), Schilling (2011, 2013), Sposito (2001, 2007) e Zaluar (2012), que contribuem de maneira inigualável para a problematização do fenômeno da violência no contexto escolar.

Nesta direção, com o intuito de encontrar pistas significativas sobre as vicissitudes da temática em pauta, a presente pesquisa objetiva analisar o modo como as expressões da violência no contexto escolar são problematizadas pelas principais publicações acadêmicocientíficas nacionais na atualidade.

Para efetivar esse estudo, de cunho marcadamente teórico, realizouse um levantamento bibliográfico dessas produções no período que compreende os anos de 2000 a 2013, nas áreas da Educação e da Psicologia.

A delimitação do período em questão se justifica por dois motivos: primeiro pelo fato de já existirem pesquisas (Abramovay, 1999; Minayo, 1999; Peralva, 2000; Sposito, 2001) que traçam um panorama investigativo minucioso sobre as relações entre violência e escola no Brasil em período anterior a este; e, segundo, porque a intenção não é a de tornar o estudo relativamente extenso, ultrapassando os limites os quais a pesquisa se propõe.

Convém enfatizar, ainda, que o presente trabalho vincula-se a uma pesquisa mais ampla, intitulada "Nas teias de Aracne: violência, linguagem e imaginário na educação escolar", cujos objetivos são: analisar a relação entre violência, linguagem e imaginário e seu impacto na educação escolar, mediante a caracterização dos aspectos semânticos e conceituais dos termos violência, linguagem e imaginário; buscar uma unidade de análise nas obras do bielorrusso Lev Semionovich Vigotski para descobrir e compreender a dinâmica da relação violência, linguagem e imaginário; e explicar o impacto da relação violência, linguagem e imaginário na educação escolar.

Portanto, é sob esse prisma que o presente estudo vislumbra assinalar desdobramentos para o fomento de novas reflexões a respeito do fenômeno da violência na escola, subsidiando a pesquisa em questão não apenas para desvelar, de forma original, pontuada e contundente, os percalços, as indagações e os conhecimentos pseudocientíficos que rondam a problemática da violência, mas também para (re)colocar a referida temática no debate atual e contemporâneo, a partir de um trabalho de elaboração conceitual e adensamento; afinal, são os diferentes modos de conceber e teorizar 
a violência que fundamentam as relações que irrompem no contexto da educação escolar.

\section{Alguns apontamentos sobre o conceito de violência}

O conceito de violência é complexo e impreciso semanticamente pelo fato de envolver aspectos sociológicos, psicológicos e filosóficos em sua definição. Por esse motivo, a compreensão desse conceito exige uma análise que ultrapasse a simples descrição etimológica do termo e/ou a menção de significados meramente superficiais.

No que diz respeito ao caráter sociológico, a violência pode ser considerada como um fenômeno provocado pela anomia social (Durkheim, 2007) no qual a perda das formas antigas de sociabilidade ainda não foram substituídas por novas normas e acordos sociais alicerçados.

Sobre o aspecto antropológico, pode-se afirmar, de acordo com Pino (2007), que a qualificação das ações humanas como violentas torna seus autores a expressão da barbárie. Neste sentido, por mais que tais ações sejam inadmissíveis frente às normas que regem a sociedade, é um equívoco imputar-Ihes a condição de irracionalidade. As ações violentas praticadas pelo homem, enquanto ser racional, sempre podem ser justificadas, por mais que sejam "provenientes do desejo gratuito de matar com requinte de crueldade, em nome do poder ou de outro motivo qualquer" (Santos, 2015, p. 185). Portanto, a violência, no sentido restrito do termo, não implica irracionalidade; logo, é característica do mundo da cultura.

No que concerne ao aspecto psicológico, a violência provoca um impacto emocional no imaginário dos indivíduos muito maior do que as próprias razões objetivas nomeadamente usadas para justificá-la. Nesse sentido, as representações sociais de violência produzidas e disseminadas pelos indivíduos e pela sociedade, em última instância, interferem na própria realidade do fenômeno.

Já do ponto de vista filosófico, pode-se depreender que existe a necessidade de encontrar um princípio racional que explique as ações ditas violentas e que Ihe confira um estatuto próprio da condição humana e de suas características.

Nesse contexto, a palavra violência dá margem a múltiplos sentidos que podem ser modificados de acordo com o potencial evocativo que os seres humanos the conferem (Pino, 2007). Por esse motivo, há grande confusão em sua definição, uma vez que esta se alimenta da experiência coletiva da humanidade, repleta de fatos violentos.

Acrescenta-se a essa discussão o fato de que, com frequência, o termo violência é associado aos conceitos de crime e/ou de agressão como se fossem sinônimos. No entanto, essa relação é um equívoco. 
Para Durkheim (2007) o crime faz parte de toda organização social humana, sem o qual nenhuma sociedade seria possível. Se relacionarmos a questão da liberdade à condição humana do homem, pode-se concluir que quem cria as regras e as leis de convivência social pode, pela mesma razão, transgredi-las, mesmo sendo algo indesejável e reprovado pela consciência social ou moral do homem. Numa sociedade, o crime é condição de existência da lei e esta é condição de existência do crime, fatos contrários que se relacionam de uma forma dialética.

Pino (2007), ao seguir as proposições de Durkheim ${ }^{2}$ (2007), afirma que o crime é caracterizado por um ato de transgressão da lei penal, - que submete seu autor a penas legais variáveis segundo as sociedades. Enquanto ato de transgressão, o crime pode ser ou não revestido por uma conotação de violência física ou moral.

No que diz respeito à agressão, é possível afirmar que entre esta e a violência há uma diferença substancial. A agressão refere-se a um componente natural, de base instintiva, ligado a mecanismos de sobrevivência.

De acordo com Pino (2007) e (Santos, 2002) a agressão refere-se a uma disposição natural existente no mundo animal para o ataque e/ou a defesa. Nesse sentido, no mundo animal, comportamentos erroneamente reconhecidos como violência, na verdade são comportamentos de agressão que se manifestam de forma natural e instintiva, regidos por fatores genéticos condicionados pelo ambiente ao longo da evolução das espécies.

Tais comportamentos implicam a adaptação dos animais à sobrevivência sendo esta uma forma de sociabilidade natural. Já na espécie humana, embora a sociabilidade natural também esteja presente, por originar-se no reino animal, torna-se cultural. Neste sentido, a sociabilidade cultural não é regida apenas por determinantes naturais, mas também de natureza histórica, de tal modo que a cultura torna-se obra exclusiva do próprio homem.

Essa transposição não é tão simples de ser compreendida, afinal, de acordo com Vigotski (2010), a atividade instintiva tanto do animal quanto do homem ainda é concebida como algo obscuro e enigmático. Para esse autor, "as causas dessa obscuridade e ausência de elucidação radicam antes de mais nada na obscuridade da própria atividade instintiva" (Vigotski, 2010, p. 79).

Portanto, é próprio da natureza ou cultura humana, através de leis ou regras, estabelecer princípios que definem as formas de organização social constituídas de interesses e conflitos diferentes. No mundo humano, embora existam impulsos agressivos naturais, são regulados por mecanismos de origem cultural pelo fato de possuírem significação para o indivíduo e serem por ele controlados. Nesse sentido, "os processos psicológicos, tal como aparecem nos animais, realmente deixam de existir; são incorporados nesse sistema de 
comportamento e são culturalmente reconstituídos e desenvolvidos para formar uma nova entidade psicológica" (Vigotski, 2007, pp. 7576).

A violência, por sua vez, é concebida como produto da cultura e determinada pelo emprego desejado, portanto racional, de uma ação humana com fins específicos. A violência apresenta-se de distintas formas no cenário social, possui um caráter histórico e relaciona-se a fatores que continuamente se dinamizam e se multiplicam.

Nessa direção, é possível depreender que existem, por um lado, contextos específicos (objetivos) favoráveis ao desenvolvimento de relações de violência e, por outro, representações de violência que participam igualmente da realidade desse fenômeno contribuindo ainda mais para sua disseminação.

$\mathrm{Na}$ esteira dessas considerações, ao focalizar a problemática da formação humana e da cultura, nota-se que a violência está longe de ser uma manifestação da irracionalidade, uma vez que remete à intencionalidade e à experiência da sociabilidade humana legitimada nas/pelas relações entre os indivíduos.

Cumpre lembrar que a definição do caráter violento de um ato depende dos valores culturais de cada grupo social, das circunstâncias em que foi praticado e até de disposições objetivas/subjetivas. Assim, em qualquer campo do conhecimento, a precisão em torno da apreensão do conceito de violência é problemática.

Diversos autores clássicos e/ou contemporâneos como Sorel (1993), Simmel (2010), D’Entrèves (1967), Arendt (2009) e Adorno (2010), ao elegerem a violência como tema de análise, destacaram a impossibilidade de atribuir um significado exato ao termo. No entanto, é importante observar que, embora o termo exprima atribuições e significados de tendência nitidamente distintas, a presença da expressão 'uso da força' provoca controvérsias sobre a licitude contextual de sua utilização.

Dessa forma, esses termos não são suficientes para abranger toda a complexidade do fenômeno em pauta, pois existem atos não considerados violentos que são expressão da violência, como a 'violência simbólica' ou a 'violência institucional' (Pino, 2007).

Alguns atos de violência atingem a sociedade como um todo, dando origem a reações proporcionalmente violentas, desestabilizando sua ordem e gerando a violência social. A violência social é prioritariamente instrumental, "por visar determinados fins políticos e/ou sociais e por usar meios físicos para sua concretização" (Pino, 2007, p. 776). Quando a violência é regida pela relação meio/fim, o ponto nodal que se instaura é que não apenas os fins justificam os meios, mas, como assevera Arendt (2009), os meios dominam os fins, fato recorrente na sociedade contemporânea em que o avanço 
tecnológico faz com que os efeitos de seu uso possam escapar do controle do homem.

Segundo Pino (2007), a propagação direta ou indireta desses meios, necessários à saída dos conflitos, constitui o motivo principal da dificuldade de controlar a violência social no mundo atual, o que torna mais complexa sua explicação. Saber que o outro pode fazer uso desses meios conduz a um ciclo hediondo da 'escalada da violência' (Pino, 2007, p. 776). Nesta perspectiva, para (Santos, 2015), a violência desestabiliza a ordem social, está presente em todas as classes sociais e tem lugar apenas no mundo dos homens.

Assim, a violência se caracteriza pela intencionalidade, pois não existe violência que não seja racional, produzida por uma motivação pessoal, afinal somente o ser racional encontra razões em suas ações, mesmo que sejam inadmissíveis para atingir seus fins, sendo isso pensável apenas na ordem da cultura.

Ao ter em conta essas discussões, nota-se que a falta de critérios na caracterização da violência pode ser conivente com um processo concomitante de reificação do ser humano e de banalização da violência. Daí a necessidade de problematizar a violência e de delimitar ao menos alguns de seus contornos conceituais. É para esse aspecto que a sociedade deve, indubitavelmente, atentar-se.

\section{Trajetória da pesquisa}

A partir de tais considerações, com o intuito de analisar o modo como as expressões da violência no contexto escolar são problematizadas pelas principais publicações acadêmico-científicas nacionais na atualidade, realizou-se um levantamento bibliográfico das principais produções teóricas nacionais publicadas no período de 2000 a 2013: livros que constam na base de dados da Biblioteca Nacional do Rio de Janeiro, depositária do patrimônio bibliográfico e documental do Brasil; e artigos científicos publicados em periódicos (Qualis A e B na classificação definida pela Coordenação de Aperfeiçoamento de Pessoal de Nível Superior - CAPES), ambos nas áreas da Educação e da Psicologia.

No processo de levantamento dos artigos, a partir do uso da palavrachave 'violência escolar' foram encontrados 2370 artigos nos periódicos CAPES. Ao filtrar a pesquisa inserindo o item 'periódicos revisados por pares' totalizou-se 1620 artigos. Na intenção de refinar ainda mais a pesquisa, utilizou-se as palavras: 'violência', 'escola', 'violência escolar', 'violência escolar no Brasil', de tal forma que restaram 142 artigos. Ao selecionar os artigos publicados no Brasil, entre 2000 e 2013, restaram apenas 43. Desse número, selecionouse através da leitura dos resumos 33 artigos, os quais foram lidos na íntegra. Porém, utilizou-se 22 artigos para a produção dos 
fichamentos bibliográficos e dos fichamentos de resumo os quais se apresentaram condizentes com os objetivos da pesquisa.

Já na pesquisa realizada no site da Biblioteca Nacional, ao limitá-la dentro do mesmo período (2000 a 2013), a partir do uso da palavrachave 'violência escolar', foi possível encontrar 37 livros publicados, embora tenham sido excluídos dessa seleção 11 livros que se referiam a edições diferentes do mesmo título. Ao utilizar a palavrachave 'violência na escola', encontrou-se 85 livros dos quais e foram selecionados 56. Dentre os 85 livros foram excluídos da seleção aqueles já relacionados na pesquisa anterior. Um dado interessante que despertou a atenção foi o fato de que dos 56 livros selecionados, 11 possuíam em seu título a menção à palavra bullying, denotando-a como sinônimo de violência, sendo que, dentre estes livros, 3 eram da categoria literatura infanto-juvenil.

Ao considerar este vasto material para leitura e a intenção de elaborar resenhas e fichamentos contendo referências bibliográficas, partes específicas que compunham a obra lida e sínteses interpretativas com as ideias centrais dos autores - a perspectiva com a qual trabalhavam, as proposições fundamentais as quais defendiam e o modo como construíam a estrutura do argumento para fundamentar a tese principal da obra -, procurou-se acentuar as proposições de Alves-Mazzotti (2012) sobre o rigor teóricometodológico ao selecionar as pesquisas presentes nas produções bibliográficas publicadas no Brasil que fundamentariam o trabalho.

Para essa autora, diversas pesquisas realizadas em educação no Brasil apresentam atualmente deficiências devido à pobreza teóricometodológica relacionada ao processo de produção, marcada, na maioria das vezes, por aspectos demasiadamente descritivos e por modismos acríticos.

Com efeito, mediante o baixo rigor teórico-metodológico, essas pesquisas não conseguem ser inseridas em contextos mais amplos. Ao valorizar o novo, sem relação com os conhecimentos consolidados em determinada área, coopera-se para a perda da qualidade nas pesquisas.

Desse modo, ao atentar-se para esse aspecto durante a seleção e leitura das pesquisas e com o intuito de efetivar o objetivo do presente estudo, foi possível depreender que a violência no contexto escolar é um problema que nas últimas décadas vem ganhando espaço cada vez maior nos meios de comunicação e em estudos e pesquisas, suscitando novas reflexões diante de suas múltiplas manifestações físicas e/ou simbólicas. Nesse contexto, a escola transforma-se em um espaço onde ocorrem situações de violência que tomam proporções assustadoras em nossa sociedade. 


\section{Expressões da violência na escola}

Ao ponderar as considerações de Alves-Mazzotti (2012) e, ainda, ao ancorar-se no referencial teórico que procurou dar sustentação à pesquisa - a Psicologia Histórico- Cultural (Vigotski, 1997, 2004) -, sistematizou-se três categorias de análise: originalidade, relevância e pertinência das discussões empreendidas; rigor no tratamento teórico-metodológico; e, contribuições teóricas para o debate sobre o tema. O delineamento destas categorias de análise permitiram refinar ainda mais o processo de garimpagem das produções teóricas selecionadas para o estudo.

Neste momento, seguindo as preleções de Vigotski (2004), depreendeu-se que para discorrer sobre a violência relacionada à educação escolar seria preciso voltar o olhar à constituição humana, permeada pela cultura como um processo em que o homem é considerado um ser biológico que se transforma nas/pelas relações sociais vivenciadas no contexto no qual está inserido (Vigotski, 1997).

Neste ínterim, considerando que a violência é um problema que abrange a sociedade em sua totalidade, inevitavelmente atinge a escola, de diversas formas e distintas razões.

No rastro dessas proposições, nota-se que na escola ressoam as turbulências sociais que traduzem os processos históricos de exclusão social aos quais milhões de crianças e jovens das classes populares estão submetidos.

Diante dos desdobramentos a respeito do fenômeno da violência escolar no Brasil e da forma de suas manifestações, é visível o impacto nas relações cotidianas educacionais e suas expressões dentro desse contexto.

Deste modo, foi possível constatar que, dentre os artigos e os livros acadêmico-científicos selecionados, alguns trabalhos se limitavam a apresentar um conteúdo meramente descritivo, com pouco aprofundamento teórico; outros tentavam fazer uma intersecção entre distintas posições teóricas, resvalando no ecletismo; e outros, ainda, faziam referências ínfimas às pesquisas correlatas, de tal forma que novas contribuições apareciam somente de forma restrita e pontuada. Neste sentido, procurou-se alinhavar os principais pontos nodais que comporiam os resultados da pesquisa a partir das contribuições mais expressivas sobre as expressões da violência na escola.

Um problema fundamental apontado por Minayo e Capurchande (2011) é que as informações sobre a violência geradas e divulgadas por fontes oficiais têm sido desqualificadas, fragmentadas e banalizadas.

Segundo Minayo e Capurchande (2011) há instituições públicas que legitimam e autorizam a circulação e o controle de informações sobre 
a violência, tratando-as como instrumentos de domínio privado e não como uma prestação de serviços à sociedade. Isso ocorre por causa das relações patrimoniais autoritárias, burocratizadas e preconceituosas que marcam as estruturas institucionais do país.

Por conseguinte, o processo de produção dessas informações além de não refletir a realidade e a intensidade dos fatos violentos, uma vez que adequa-se às concepções dominantes de violência e de indivíduos violentos que perduram hegemonicamente em nossa sociedade, ainda cria uma zona de invisibilidade a despeito de determinadas formas de violência existentes.

Cabe sinalizar a relevância em apreender o fenômeno dentro do seu contexto, não se atendo apenas à forma como se apresenta, mas buscando a interpretação daquilo que é considerado ou não como violência para os indivíduos que a estão vivenciando.

Nesse ínterim, faz-se necessário buscar estratégias de análise que considerem as informações divulgadas sobre violência como um direito do cidadão e não como um 'produto' de uso mercadológico próprio das instituições sociais, uma vez que estas informações interferem nas práticas e nas representações que diferentes grupos elaboram acerca do fenômeno da violência em nosso país.

Acrescenta-se a essa discussão os estudos de Sposito (2001), quem analisa a produção científica sobre a violência nas escolas no Brasil e indica que ocorreram mudanças no padrão da violência escolar no decorrer do tempo. Segundo a autora, na década de 1980, os atos de vandalismo, como: a violência contra o patrimônio, as depredações e as invasões dos prédios escolares eram comuns. A partir da década de 1990, os atos de violência interpessoais ganharam destaque, principalmente entre os alunos. Nesse contexto, se na década de 1980 a violência atingia principalmente as escolas dos grandes centros urbanos, nas décadas seguintes, a violência ascendeu em municípios de médio porte e menos industrializados.

Por esse motivo, de acordo com Sposito (2001), a partir da década de 1990, a instituição escolar passou a ser permeada por um quadro complexo regido pelas formas de violência, sobretudo em regiões marcadas pela presença do crime organizado e do narcotráfico.

Nesse período, se por um lado os trabalhos acadêmico-científicos não interrogavam as formas de sociabilidade entre os alunos, por outro, criticavam as práticas internas aos estabelecimentos escolares, responsabilizando-os pela produção da violência em seus contextos.

Já nos anos 2000, a necessidade de ampliação do sistema de ensino no Brasil e as batalhas pelo ingresso à escola, marcadas pelo reconhecimento da educação como direito e como meio de mobilidade social pelas classes populares, promoveram um aumento intenso da violência escolar. Em outros termos, como a escola não estava conseguindo cumprir, de fato, a sua função social por causa das determinações impostas pela reestruturação do modelo produtivo 
capitalista, as mais sólidas utopias começaram a ser abaladas, de tal forma que as relações entre os alunos e a escola se instituíram em meio a condições cada vez mais precárias de escolarização.

Nesse sentido, a ampliação de acesso aos sistemas de ensino, acompanhada da promessa ilusória de inclusão das novas gerações no mercado de trabalho, foi responsável não apenas pelo surgimento de questionamentos a respeito da eficácia socializadora da escola, como também pela consolidação de processos de resistência que eclodiram como possíveis manifestações de violência.

A partir de tais considerações é possível encontrar indícios que revelam as expressões da violência no contexto escolar. No entanto, essas manifestações seriam de fato, caracterizadas como violência?

Para buscar respostas a essa questão, não se trata de investigar somente os atos paroxísticos provocados pelo fenômeno da violência, uma vez que seguir esse caminho representaria incorrer em uma análise precária, balizada pela fragilidade e incapaz de possibilitar uma apreensão mais profunda acerca do tema. Faz-se necessário empreender uma problematização teórica, ainda que seja breve, visando a realidade que se coloca.

Em uma pesquisa realizada por Câmara, Caliman, Capanema, Gomes \& Galvão (2010), evidenciou-se que há parâmetros classificatórios distintos entre docentes e discentes sobre o conceito de violência e sobre os aspectos que caracterizaram o fenômeno da violência no contexto escolar. Essa pesquisa mostrou, ainda, que a violência não está ligada à classe social dos alunos.

Njaine \& Minayo (2003), por sua vez, ao analisarem os significados da violência e as formas como esse fenômeno se manifesta no universo escolar, afirmam que a classe social, a natureza da instituição (pública ou privada) e os aspectos culturais e de gênero são mediadores das relações de violência que emergem no universo escolar.

No mesmo estudo, as autoras constataram que em escolas em que há o predomínio de relações violentas fisícas/simbólicas, cria-se um imaginário de violência que se relaciona à exaltação e ao poder de desafiar normas de convívio social.

Para as autoras, a ruptura do preconceito, do medo, da angústia e do silêncio face ao conhecimento de situações de violência contribuem para a instauração de um campo de prevenção da violência no ambiente escolar.

Camacho (2001), em contrapartida, ao debruçar-se sobre a mesma temática, afirma que o ambiente escolar é um espaço em que os alunos constroem e elaboram experiências de violência. Para a autora, a vulnerabilidade social, o preconceito e a discriminação invadem o contexto escolar enfraquecendo o potencial de socialização da escola, interferindo no espaço relacional e fazendo com que os 
alunos edifiquem a violência como uma configuração de experimentação escolar.

Cabe sublinhar que a violência simbólica, para Camacho (2001), por ser caracterizada prioritariamente pela dissimulação, refere-se a uma experiência aniquiladora tal qual a violência física, uma vez que incide em múltiplos níveis de relações e em seus mais variados arranjos, justamente por ter tanto alunos como professores e funcionários como agentes de produção.

Já Ruotti (2010), afirma que a violência na escola pode ser apontada como a distorção do significado da autoridade, sobretudo na sociedade brasileira, tanto na forma como o termo vem sendo apreendido quanto nas práticas que revela.

Ao seguir as asserções de Bourdieu (2001), a autora esclarece que parte da violência cometida pelos alunos na escola se relaciona diretamente ao cotidiano da própria escola, emergindo como reflexo à violência institucional, dirigindo-se aos seus representantes e, por conseguinte, irrompendo não como ruptura, mas como reprodução da violência vivenciada.

De fato, as proposições de Bourdieu (2005) acerca da 'teoria da reprodução' explicita que há situações em que a violência não é sentida por aqueles que a sofrem precisamente porque é dissimulada, naturalizada e imposta de modo arbitrário e sem questionamento por uma classe dominante às demais classes sociais.

De acordo com essa vertente, são os mecanismos propriamente escolares que começam a ser denunciados como reprodutores das desigualdades presentes na sociedade. Diante desse quadro de exclusão, a violência torna-se uma das estratégias de luta dos alunos. Nessa direção, Sposito (2007) afirma que a violência pode ser concebida como uma das condutas mais visíveis de recusa das crianças e dos jovens a um conjunto de valores impostos e representados simbólica e materialmente no interior da instituição escolar. Estes valores, por sua vez, não atendem ao universo das necessidades desse público específico que a cada dia trilha percursos de cidadania em meio a contextos extremamente desumanos.

Ainda de acordo com Sposito (2007), outra modalidade de resposta demasiadamente frequente na escola é a expressão do retraimento, da indiferença e da impermeabilidade das crianças e jovens às ações da instituição escolar.

Para acrescentar aspectos a essa discussão, Debarbieux (2007) explica que a violência escolar pode ser classificada como todo ato que dificulta, em sentido amplo, o desenvolvimento dos atores sociais presentes. Trata-se da negação dos direitos básicos e de iniquidade à cidadania. Nesse sentido, há violência em ações conscientes cujo propósito é impedir que um indivíduo ou grupo tenha a possibilidade de exercer plenamente os seus direitos. Estas ações podem ser implícitas ou explícitas e provocar danos físicos e/ou psicológicos que 
se expressam através da indiferença, do desrespeito e da ausência de reconhecimento social do outro.

Paradoxalmente, as ações contra a violência no contexto escolar, quando não são pautadas em medidas repressivas, revelam uma luta social norteada pela participação da sociedade e pelo respeito aos direitos humanos que impede o dilaceramento da cidadania e faz com que a escola se torne um espaço efetivamente democrático que prima pela transformação da realidade social brasileira.

Com relação a essa afirmação, nota-se que compreender as práticas de violência e superá-las implica esforços de entendimento sobre a atuação socializadora da escola e as representações solidificadas a respeito dos conhecimentos tácitos marcados pelo ideário neoliberal.

Dessa forma, a quebra do modelo de escolaridade voltado para a mobilidade social coexiste com o enfraquecimento da capacidade socializadora da escola como instituição formadora de novas gerações. Assim, um dos mais importantes desafios é a análise das vicissitudes que permitem à escola a redefinição de sua presença no universo das crianças e dos jovens como espaço social específico e privilegiado de promoção e desenvolvimento da cidadania. Isso porque, se de um lado a escola constitui um lugar específico para refletir sobre temas que envolvem crianças e jovens, pais e filhos, professores e alunos, de outro também se consolida como espaço distinto e privilegiado onde a socialização, a promoção da cidadania, a formação de atitudes e o desenvolvimento pessoal podem ser efetivamente concretizados.

Abordar novos significados que apenas sinalizam algum valor positivo para as crianças e jovens na vida escolar e definir práticas pedagógicas que acenam somente para possibilidades incertas de melhorias futuras não constituem aspectos suficientes para edificar relações realmente significativas no processo de mediação entre os alunos e a instituição escolar. Na ausência de outros apontamentos, a indiferença e a violência tornam-se respostas constantes e banalizadas, além de constituir um sinal preocupante de tensão que atinge os sistemas escolares.

Nesse cenário é indispensável pensar em estratégias de prevenção e de combate à violência escolar. O problema é que, geralmente, a perspectiva de um trabalho de prevenção na escola só acontece motivada por situações emergenciais, favorecendo a distorção dos legítimos objetivos como prática social institucionalizada.

Em face ao quadro alarmante que se configura e revela os altos índices de violência no contexto escolar, é possível notar a predominância de iniciativas públicas - estendidas em nível estadual e municipal e advindas do Ministério da Justiça -, que objetivam reduzir a violência escolar, como a inserção da ronda policial nos arredores e nos espaços das escolas e universidades, sob a 
justificativa de que jovens (e até mesmo crianças) estão envolvidos em homicídios, com o crime organizado e o narcotráfico.

Segundo Gonçalves \& Sposito (2002), a violência escolar tem gerado medo e pânico no interior dos estabelecimentos de ensino, promovendo a inserção de medidas (paliativas) de controle e vigilância sobre as crianças e os jovens de maneira restrita, como o policiamento nas escolas e a instalação de detectores de metal e de câmaras nos corredores e pátios das escolas, principalmente nas instituições da rede particular de ensino.

Deste modo, diante de situações de violência, a escola adota com frequência medidas repressivas que 'aparentemente' procuram resolver o problema. No entanto, enfrentar a violência requer iniciativas em vários níveis e diferentes complexidades em longo prazo.

O problema na implantação de novas práticas no espaço escolar, exige uma extensa participação de todos os envolvidos nos processos escolares (diretor, coordenador, psicólogos escolares, professores, alunos, demais funcionários da escola, pais e comunidade). Entretanto, nem sempre essa participação se consolida, seja por deficiências estruturais (como a carência de recursos materiais e humanos), seja pela precariedade na formação dos profissionais de educação ou na consolidação de uma gestão democrática efetiva. Estes fatores, dentre outros, dificultam a promoção de uma escola inclusiva e democrática, onde os direitos do outro e os valores de respeito recíprocos são enfatizados.

Destarte, uma formação apropriada dos profissionais da área da Educação e da Psicologia, aliada à melhoria das condições de trabalho, principalmente nas escolas públicas, é condição para viabilizar uma práxis pedagógica que priorize as necessidades educacionais e psicossociais dos alunos.

\section{Considerações finais}

Apesar de a Psicologia Histórico-Cultural nortear todo o processo de levantamento bibliográfico realizado, um maior aprofundamento da relação entre o aporte teórico em questão e os artigos e livros selecionados poderá ser vislumbrado em pesquisas futuras ou na própria pesquisa mais ampla ao qual este estudo está vinculado conforme foi mencionado na introdução -, uma vez que a intenção é a de não ultrapassar os limites do artigo.

Portanto, essa pesquisa, guiada pela Psicologia Histórico-Cultural buscou analisar o modo como as expressões da violência no contexto escolar são tratadas nas principais produções teóricas publicadas no Brasil no período de 2000 a 2013. 
Com esse objetivo, e com o intuito de reiterar a premissa de que a violência possui uma significação que é marcada pela racionalidade, pela qualificação das ações humanas e por uma intenção claramente definida, procurou-se analisar, ainda que brevemente, a concepção de violência presente na literatura especializada no assunto.

Embora não se tenha abordado densamente a noção de violência, uma vez que há diversos teóricos clássicos da literatura especializada no assunto que já o fazem e que foram neste trabalho mencionados, foi possível identificar que o fenômeno da violência conjetura ações e representações que promulgam a produção simbólica dos sujeitos, tendo em vista que se revela tanto através de manifestações físicas, quanto de expressões de caráter emblemático.

Historicamente, o conceito de violência, bem como o próprio fenômeno, se desenvolveu entrelaçado nas/alicerçado sob as relações dos indivíduos entre si e com a sociedade.

A violência se caracteriza quando os atores sociais nela envolvidos assim a qualificam, ratificando um consenso social a respeito. É, portanto, compreendida como produto de um determinado tempo/contexto histórico. Nesse sentido, é possível afirmar que há expressões da violência que, dada a sua invisibilidade, são imensamente maiores do que se pode imaginar.

Nesta direção, a violência, ao constituir-se como um fenômeno simultaneamente social, por relacionar-se às condições históricas que determinam os limites das ações do homem em sociedade;, e individual, por referir-se à escolha de cada ser humano que decidirá se irá ou não respeitar os limites convencional e socialmente acordados, é um aspecto do livre arbítrio humano "susceptível (sic) de educação, uma vez que não há nada, nem do ponto de vista genético, nem do ponto de vista do meio físico ou social“ (Pino, 2007, p. 780), que determina exclusivamente o modo de agir do homem.

Nessa ambiência, quando se transpõe a discussão para o contexto escolar, nota-se que a ampliação quantitativa e qualitativa da violência social gera uma tensão caracterizada por movimentos imprevisíveis, determinando uma atmosfera de insegurança e de desconfiança no interior e entre os membros da comunidade escolar. É preciso destacar que essa tensão produzida incide sobre o processo ensino-aprendizagem, assim como sobre a relação professor-aluno, enquanto núcleos da instituição escolar. Portanto, a violência na escola, além de contribuir para que ocorra a evasão e o fracasso escolar, ainda corrobora o rebaixamento da qualidade do ensino e a exclusão social. Portanto, o problema da violência deve ser tratado essencial e previamente como uma questão educativa e social.

Deste modo, convém à sociedade, em geral, e à escola, em particular, refletirem e debaterem assuntos que assolam a humanidade em seu cotidiano, dentre os quais a violência se destaca, incluindo os modos de prevenção e as repercussões possíveis no 
desenvolvimento da criança e do jovem. É preciso reconhecer que o campo da convivência em sociedade ecoa diretamente nos processos de socialização, como base e condição fundante em que se assenta a defesa dos direitos humanos.

Como os educandos são seres individuais, de natureza social, uma vez que, segundo Vigotski (2004, p. 82), "a vertente individual se constrói como derivada e secundária sobre a base do social", pode-se dizer que, ao mesmo tempo em que são afetados pela escola e pela sociedade, são capazes de arquitetar a si próprios. Daí a possibilidade de encontrar caminhos possíveis para percorrer e lidar com a problemática da violência, instaurando espaços democráticos, de diálogo e de busca pela coletividade.

As expressões da violência na escola, longe de serem manifestações de irracionalidade, referem-se a elementos mediadores concretos da ordem da cultura que instituem e são instituídos pela atividade humana. Tem-se, portanto, a constituição de um fenômeno complexo, que não está restrito à realidade interna da escola, nem tampouco ao próprio indivíduo, mas que coloca em destaque questões inextricavelmente relacionadas a aspectos históricos, econômicos, políticos e sociais de determinada época/sociedade.

Portanto, concluiu-se, de modo particular, que trabalhos futuros sobre a temática da violência na escola devem avançar em aspectos até o momento pouco desenvolvidos nas pesquisas existentes; e, de modo geral, que um caminho plausível para minimizar a violência na educação escolar aponta para a ênfase em práticas participativas na relação escola e comunidade, para a construção da sociabilidade voltada para a formação da cidadania, para a concretização da democracia e para o reconhecimento da dignidade humana.

\section{Referências}

Abramovay, M. (1999). Gangues, galeras, chegados e rappers. Rio de Janeiro: Garamond.

Abramovay, M. \& Castro, M. G. (2006). Caleidoscópio das violências na escola. Brasília: Missão Criança.

Adorno, T. W. (2010). Educação e Emancipação (4rd ed). Rio de Janeiro: Paz e Terra.

Alves-Mazzoti. A. J. (2012). A revisão da bibliografia em teses e dissertações: meus tipos inesquecíveis - o retorno. In Bianchetti, L.; Machado, A. M. N. (Orgs.). A bússola do escrever: desafios e estratégias na orientação de teses e dissertações (3ed pp. 24-44). São Paulo: Cortez.

Antunes, R. (2011). Dimensões da crise contemporânea ou da nova (des)ordem internacional. In Antunes, R. Adeus ao trabalho: 
ensaio sobre as metamorfoses e a centralidade no mundo do trabalho (15th ed pp. 161-165). São Paulo: Cortez.

Arendt, H. (2009). Sobre a violência. Rio de Janeiro: Civilização Brasileira.

Bakhtin, M. (1988). Marxismo e filosofia da linguagem. São Paulo: Hucitec.

Bourdieu, P. (2001). Meditações pascalianas. Rio de Janeiro: Bertrand Brasil.

Bourdieu, P. (2005). O poder simbólico (4th ed.). Rio de Janeiro: Bertrand Brasil.

Camacho, L. M. Y. (2001). As sutilezas das faces da violência nas práticas escolares de adolescentes. Educação e Pesquisa, 27(1), 123-140.

Câmara, J., Caliman, G., Capanema, C., Gomes, C. A., \& Galvão, A. (2010). Violências escolares: implicações para a gestão e o currículo. Ensaio: Avaliação e Políticas Públicas em Educação, 18(68), 425-442.

Debarbieux, E. (2007). Violência na escola: um desafio mundial? Lisboa: Instituto Piaget.

D'entreves, A. P. (1967). The notion of State: an introduction to political theory. London: Oxford University Press.

Durkheim, E. (2007). As regras do método sociológico (3rd ed.). São Paulo: Martins Fontes.

Gonçalves, L. A. O., \& Sposito, M. P. (2002). I niciativas públicas de redução da violência escolar no Brasil. Cadernos de Pesquisa, 115, 101-138.

Guimarães, A. M. (2010). Novos regimes de ver, ouvir e sentir afetam a vida escolar. Educação, 35(3), 413-430.

Minayo, M. C. S. (1999). Fala galera. Rio de Janeiro: Garamond.

Minayo, M. C. S., \& Capurchande, R. D. (2011). A violência faz mal à saúde e à qualidade de vida: conceitos, teorias e tipologias de violência. In Njaine, K., Minayo, M. C. S., Souza, E. R., Teles, M. N., Constantino, P., \& Capurchande, R. D. et al (Orgs) Impactos da Violência: Moçambique e Brasil (pp. 39-82). Rio de Janeiro: FIOCRUZ.

Njaine, K. \& Minayo, M. C. S. (2003). Violência na escola: identificando pistas para a prevenção. Interface: comunicação, saúde, educação, 7(13), 119-134.

Patto, M. H. S. (2007). Escolas cheias, cadeias vazias: nota sobre as raízes ideológicas do pensamento educacional brasileiro. Estudos Avançados, 21(61), 243-266.

Peralva, A. (2000). Violência e democracia: o paradoxo brasileiro. Rio de Janeiro: Paz e Terra.

Pino, A. (2007). Violência, educação e sociedade: um olhar sobre o Brasil contemporâneo. Educação \& Sociedade, 28(100), 763785. 
Ruotti, C. (2010). Violência em meio escolar: fatos e representações na produção da realidade. Educação e Pesquisa, 36(1), 339355.

Santos, S. D. M. (2002). Sinais dos tempos: marcas da violência na escola. Campinas, SP: Autores Associados.

Santos, S. D. M. (2015). Retratos do cotidiano escolar: violência, linguagem e exclusão social. In Hur, D. U, Lacerda Júnior, F., Resende, M. R. (Orgs) Psicologia e transformação: intervenções e debates contemporâneos. (pp. 177-199). Goiânia, GO: UFG.

Schilling, F. I. (2011). Educação em direitos humanos: reflexões sobre o poder, a violência e a autoridade na escola. São Paulo: CDHEP.

Schilling, F. I. (2013). I gualdade, desigualdade e diferenças: o que é uma escola justa? Educação e Pesquisa, 39(1), 31-48.

Simmel, G. (2010). Sociologie étude sur les formes de la socialization. Paris: PUF.

Sorel, G. (1993). Reflexões sobre a violência. São Paulo: Martins Fontes.

Sposito, M. P. A. (2001). Um breve balanço da pesquisa sobre violência escolar no Brasil. Educação e Pesquisa, 27(1), 87-103.

Sposito, M. P. (2007). Violência e escola: as múltiplas facetas de uma relação. In Pacheco, E.D. (Org.). O cotidiano infantil violento: marginalidade e exclusão social (pp. 53-66). São Paulo: Editora L/FAPESP.

Vigotski, L. S. (1997). Obras escogidas. Madrid: Visor Distribuciones.

Vigotski, L. S. (2004). Teoria e método em psicologia. (3nd ed.). São Paulo: Martins Fontes.

Vigotski, L. S. (2007). A formação social da mente. (8th ed). São Paulo: Martins Fontes.

Vigotski, L. S. (2010). Psicologia pedagógica. (3nd ed.). São Paulo: Martins Fontes.

Zaluar, A. (2012). Juventude violenta: processos, retrocessos e novos percursos. Dados, 55(2), 327-355.

\section{Endereço para correspondência}

Karin Cristina de Souza Moraes Magalhães

Universidade Federal de Goiás

Faculdade de Educação

Rua 235, 307, Setor Leste Universitário, CEP 74605-050, Goiânia - GO, Brasil

Endereço eletrônico: karinmmagalhaes@gmail.com

\section{Sheila Daniela Medeiros dos Santos}

Universidade Federal de Goiás

Faculdade de Educação

Rua 235, 307, Setor Leste Universitário, CEP 74605-050, Goiânia - GO, Brasil

Endereço eletrônico: sheiladmsantos@gmail.com

Recebido em: 05/02/2015

Reformulado em: 18/09/2015 
Aceito para publicação em: 28/10/2015

\section{Notas}

* Graduanda em Pedagogia na Universidade Federal de Goiás.

** Doutora em Educação. Docente do Programa de Pós-Graduação em Psicologia.

${ }^{1} \mathrm{O}$ termo contemporaneidade, neste artigo, não faz alusão meramente a um tempo específico de periodização da história ocidental, mas sinaliza os processos marcados por transformações complexas que ocorrem nas esferas econômica, política, social e histórica, conforme acepção de Antunes (2011).

2 Apesar de o referencial epistemológico de Durkheim (2007) estar pautado no positivismo clássico, esse autor oferece algumas pistas interessantes para se pensar a noção de crime. 